\title{
Implications of depositional environment on the iodine enrichment in the sedimentary system: evidences from the $\mathbf{N}$-alkane in sediments
}

\author{
Xiaobin Xue ${ }^{1,3, *}$, Junxia $\mathrm{Li}^{1,2,3}$, and Yanxin Wang ${ }^{1,3}$ \\ ${ }^{1}$ State Key Laboratory of Biogeology and Environmental Geology, China University of Geosciences, \\ 430074Wuhan, China \\ ${ }^{2}$ Laboratory of Basin Hydrology and Wetland Eco-restoration, China University of Geosciences, \\ 430074Wuhan, China \\ ${ }^{3}$ School of Environmental Studies, China University of Geosciences, 430074 Wuhan, China
}

\begin{abstract}
To understand the implications of depositional environment on the enrichment of iodine in sediments, the $\mathrm{N}$-alkane analysis has been conducted on the sediment from the North China Plain (NCP). The iodine contents of sediments ranged from 0.03 to $2.54 \mu \mathrm{g} / \mathrm{g}$ with the highest content occurring in the depth of 170-185 m. The results of sediment $\mathrm{N}$ alkane (TAR, $\Sigma \mathrm{T} / \Sigma \mathrm{M}$ and ACL) indicate that the marine source input is the predominant factor controlling the enrichment of iodine in the groundwater system. The $\mathrm{Pr} / \mathrm{Ph}$ ratios (from 0.13 to 1.68 ) and the plot of $\mathrm{Pr} / \mathrm{n}-\mathrm{C}_{17}$ vs. $\mathrm{Ph} / \mathrm{n}-\mathrm{C}_{18}$ suggest that sediments deposited under suboxic to anoxic conditions. Under the oxdizing conditions, the iodine tends to be rich in the sediment, while the iodine may prefers to be released into groundwater under the reducing conditions.
\end{abstract}

\section{Indroduction}

Iodine is one of essential trace elements in human body, which is known as "intelligence element". The biogeochemical cycle of iodine is of great concern to many researchers ${ }^{[1,2]}$, especially the enrichment of iodine in groundwater system ${ }^{[2,3,4]}$, and watersediment interactions have a great impact on the occurrence of high iodine groundwater. It is critical to understand the sources and mobilization mechanisms of iodine in sedimentary system.

The North China Plain (NCP), bounded by the Bohai Sea to the east, takes groundwater as the main source of drinking water, however, millions of residents are threatened by waterborne rich iodine ${ }^{[3,4]}$. Although some studies have been conducted to understand the occurrence of high iodine groundwater at NCP ${ }^{[2,3,4]}$, the source of iodine in sediments is still not well understood. In this study, we analyze the $\mathrm{N}$-alkane in the borehole sediments collected from a known iodine-contaminated site at NCP to understand the relationships between iodine in sediment and depositional environment.

\footnotetext{
*Corresponding author: xbxue@cug.edu.cn
} 


\section{Method}

Core CZ16 is located at the Cangxian County with GPS position (N 38 19'60", E $117^{\circ} 2^{\prime} 28.25^{\prime \prime}$, elevation $8 \mathrm{~m}$ ). The depth of the core is $420 \mathrm{~m}$, and the average recovery is more than $90 \%$. The majority of the core is composed of yellowish-brown, steel gray and reddish-brown clayey silt and silty clay interbedded clay and sand layers. The sediment samples were collected from $80 \mathrm{~m}$ to $410 \mathrm{~m}$.

Sediment samples (total 45) were freeze dried and ground into a fine power. The iodine of sediment was extracted using $10 \%$ dilute ammonia after being pressurized for decomposition at $190^{\circ} \mathrm{C}$ for $19 \mathrm{~h}$, which was developed by previous studies ${ }^{[5,6]}$, and further measured using ICP-MS (Aglient 7900). The precision and accuracy of the sample preparation and instrumental performance were checked using several international reference standards of iodine concentration (GSS-1, GSS-4, GSS-7). The precision in terms of maximum observed relative standard deviation (RSD) on repeated measurements of the reference standards is $<5 \%$.

Hydrocarbon compositions of 26 selected sediment samples were measured after being air-dried in the dark and ground to through 100 mesh sieve. As much as $20 \mathrm{~g}$ of each sample was Soxhlet-extracted with dichloromethane (DCM) for $72 \mathrm{~h}$ with native copper added to remove sulfur. The extract was concentrated on a rotary evaporator under reduced pressure and transferred to a small vial $(1 \mathrm{~mL})$. The hexane-solute organic compounds were separated into three fractions using a column packed with activated alumina and silica gel $(2: 1)$, by elution with hexane (saturated hydrocarbon), hexane/DCM (aromatic), and methanol (MeOH) (non-hydrocarbon) ${ }^{[7]}$. The hydrocarbons were then analyzed by GC-MS (Agilent 6890N/5975MSD), equipped with an on-column injector. An HP-5 MS capillary column $(30 \mathrm{~m} \times 0.25 \mathrm{~mm} \times 0.25 \mu \mathrm{m})$ was used. The operating conditions were as follows: temperature increase from 80 to $290^{\circ} \mathrm{C}$ at $5^{\circ} \mathrm{C} / \mathrm{min}$, finally held at $290^{\circ} \mathrm{C}$ for $30 \mathrm{~min}$; He as carrier gas; the ionization energy of the mass spectrometer set at $70 \mathrm{eV}$; and the scan range from 50 to $550 \mathrm{amu} / \mathrm{s}$. The identification of compounds was based on published literature and the NIST chemical data library. The quantification was made by comparing individual peak area with that of a known concentration of internal standard (C14-N-alkane, Dr Ehrenstorfer, Germany). Four blank samples were also analyzed following the same procedures as the sediment samples. This work was done at State Key Laboratory of Biogeology and Environmental Geology, China University of Geosciences.
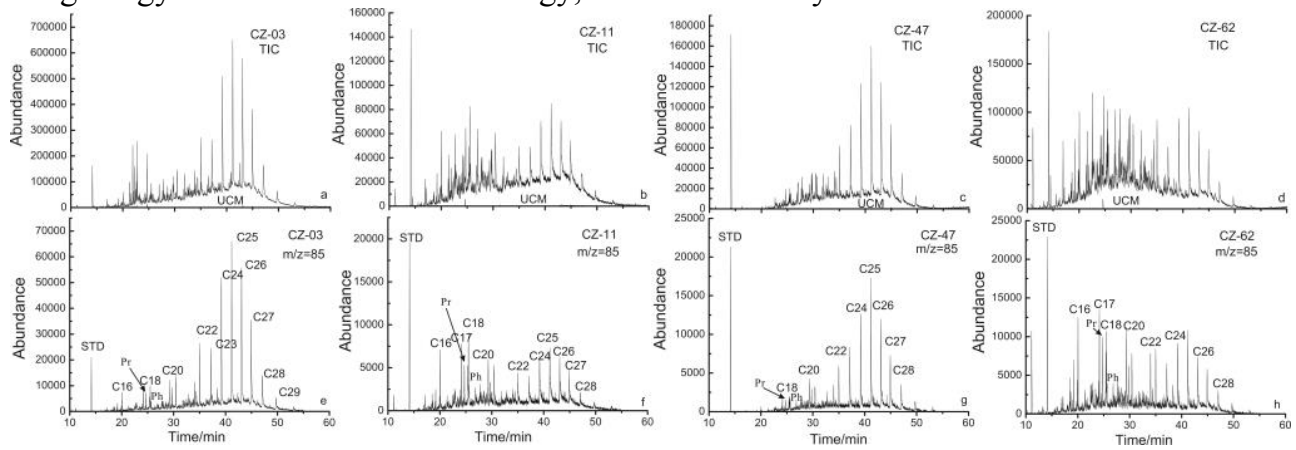

Fig. 1. Mass chromatograms of total ion current (TIC) (a, b, c, d) and n-alkanes (e, f, g, h) in sediments from the Datong Basin. STD denotes standard. Numbers indicate carbon chain length of $\mathrm{n}$ alkanes. 


\section{Result and discussion}

\subsection{N-alkane}

Sedimentary saturated hydrocarbons consist of resolved compounds (mostly n-alkanes) and unresolved complex mixtures (UCM). The contents of total n-alkanes in the sediment samples ranged from 5.06 to $1394 \mathrm{ng} / \mathrm{g}$ and normal alkanes in the extracts mainly shifted from $\mathrm{C} 16$ to $\mathrm{C} 31$ (Fig. 1). The presence of UCMs indicates the presence of petroleumsourced OM in the sediment samples that have been biodegraded. The ditribution of nalkanes in $64 \%$ sediment samples are characterized by the unimodal distribution and dominated by HMW (higher molecular weight) n-alkanes. Other sediment samples present a bimodal distribution of n-alkanes, which have a clear even carbon number predominance, especially for low carbon n-alkanes. Microbial activities preferentially utilize the lower molecular weight n-alkanes, thereby eliminating the odd-over-even predominance. There is a reasonable assumption that low carbon and odd carbon n-alkanes are reduced by microbes or autochthonous bacteria ${ }^{[8]}$. Furthermore, even carbon number n-alkanes are preferentially produced in highly saline and carbonate environments where aerobic and anaerobic bacteria have subsisted on the remains of algae ${ }^{[9]}$, which is related to Bohai Sea. The cross-plot of $\mathrm{Pr} / \mathrm{n}-\mathrm{C} 17$ and $\mathrm{Ph} / \mathrm{n}-\mathrm{C} 18$ clearly exhibit that the $\mathrm{OM}$ input is derived from both terrestrial and marine constituents (Fig. 3a).

Table 1. Diagnostic ratios and design formulas from n-alkanes in sediment.

\begin{tabular}{|c|c|}
\hline Diagnostic ratios & Design formulas \\
\hline $\begin{array}{l}\text { Carbon Preference } \\
\text { Index (CPI) }\end{array}$ & $\begin{array}{c}\mathrm{CPI}_{1}=1 / 2\left[\sum \mathrm{C}_{17 \sim 23}(\text { odd }) / \sum \mathrm{C}_{16 \sim 22}(\text { even })+\sum \mathrm{C}_{17 \sim 23}(\text { odd }) / \sum \mathrm{C}_{18 \sim 24}(\text { even })\right] \\
\mathrm{CPI}_{2}=1 / 2\left[\sum \mathrm{C}_{25 \sim 33}(\text { odd }) / \sum \mathrm{C}_{24 \sim 32}(\text { even })+\sum \mathrm{C}_{25 \sim 33}(\text { odd }) / \sum \mathrm{C}_{26 \sim 34}(\text { even })\right] \\
\mathrm{CPI}=\sum \mathrm{C}_{15 \sim 33}(\text { odd }) / \sum \mathrm{C}_{16 \sim 34}(\text { even })\end{array}$ \\
\hline $\begin{array}{l}\text { Terrigenous/aquatic } \\
\text { ratio (TAR) }\end{array}$ & $\mathrm{TAR}=\sum \mathrm{C}_{27+29+31} / \sum \mathrm{C}_{15+17+19}$ \\
\hline $\begin{array}{c}\text { Terrigenous/Marine } \\
(\Sigma \mathrm{T} / \Sigma \mathrm{M})\end{array}$ & $\Sigma \mathrm{T} / \Sigma \mathrm{M}=\sum \mathrm{C}_{25 \sim 35} / \sum \mathrm{C}_{15 \sim 21}$ \\
\hline $\begin{array}{l}\text { Average Chain Length } \\
\text { (ACL) }\end{array}$ & $\mathrm{ACL}=\sum\left(\mathrm{C}_{\mathrm{i}} \times \mathrm{i}\right) / \sum \mathrm{C}_{\mathrm{i}}(\mathrm{i}=15 \sim 35)$ \\
\hline
\end{tabular}

The distribution of these biomarkers was used to assess the source(s) of these compounds based on diagnostic ratios as discussed below. The carbon preference index(CPI) values were estimated for lower molecular weight $n$-alkanes and higher molecular weight $n$-alkanes as $\mathrm{CPI}_{1}$ and $\mathrm{CPI}_{2}$, respectively (Table 1 ). $\mathrm{CPI}, \mathrm{CPI}_{1}$ and $\mathrm{CPI}_{2}$ values ranging from 0.59 to 1.01 , from 0.38 to 1.03 and from 0.58 to 3.4 suggest that the organic matter of sediment is derived from natural petroleum hydrocarbon and has undergone biodegradation ${ }^{[10]}$. TAR value ranges from 0.34 to 10.5 , corresponding well with the values of $\sum \mathrm{T} / \sum \mathrm{M}(0.62-8.2)$ and $\mathrm{ACL}(21.9$ - 25.05), and indicates a dominant of input of terrestrial OM as well as marine influence ${ }^{[11]}$. The Pristane / Phytane $(\mathrm{Pr} / \mathrm{Ph})$ ratio is an effective tool for indication the redox environment during sedimentation and diagenesis [7]. In this respect, the $\mathrm{Pr} / \mathrm{Ph}$ ratios (0.13-1.68) suggest that sediments deposited under suboxic to anoxic conditions in the study area. The $\mathrm{Pr} / \mathrm{Ph}$ ratios are almost lower than 1 , indicating reductive environment, while sediments with $\mathrm{Pr} / \mathrm{Ph}$ ratios more than 1 deposites in oxidizing environment. In addition, Pristane $/ n-C_{17}$ versus Phytane $/ n-C_{18}$ for the analyzed sediment samples infer oxicity whereby both the oxic and anoxic conditions can be 
discovered (Fig. 3a). The fluctuation of redox environment is exactly where the iodine concentration increases in sediments (Fig. 2), suggesting potentially the effects of changes of palaeo-environment and palaeo-climate. During the Pleistocene, global climate was characterized by enhanced glacial-interglacial cycles, which led to large sea-level fluctuations and the occurrence of marine transgression and regression in coastal plain. The redox condition shows a change at the depth of 170-185 m, corresponding respectively to the top and bottom of reported Haixing marine transgression horizon ${ }^{[12]}$. This may indicate the impacts of palaeo-environment on the sedimentary system, especially the cycling of marine transgression and regression.

$$
\text { Iodine }(\mu \mathrm{g} / \mathrm{g})
$$

N-alkane (ng/g)

TAR

$\mathrm{ACL}$

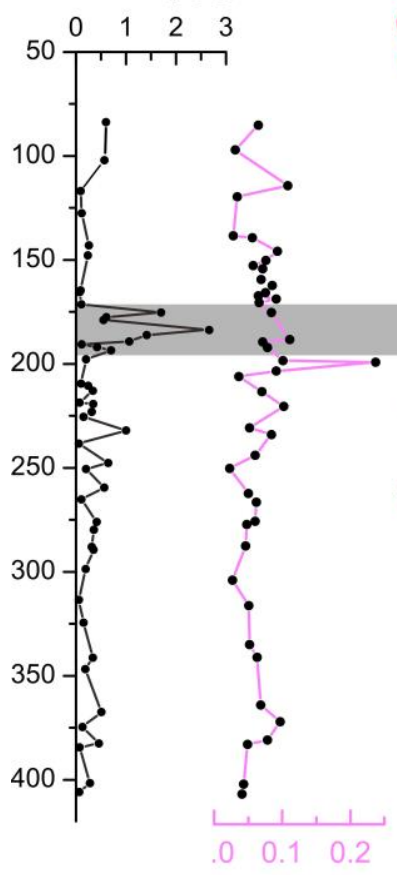

0200400600

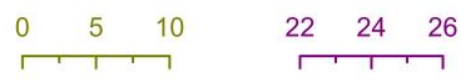

$1,1,1,1,1,2000$

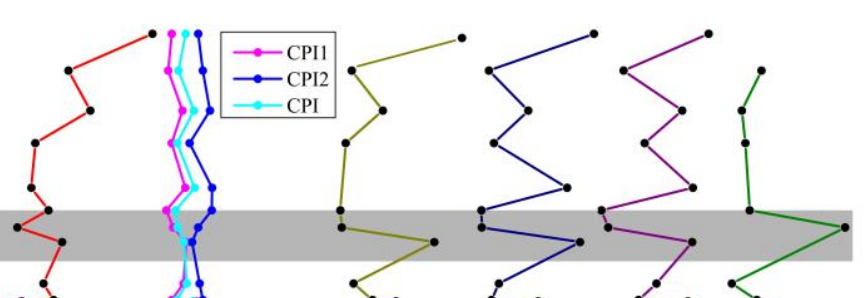

TOC (\%)

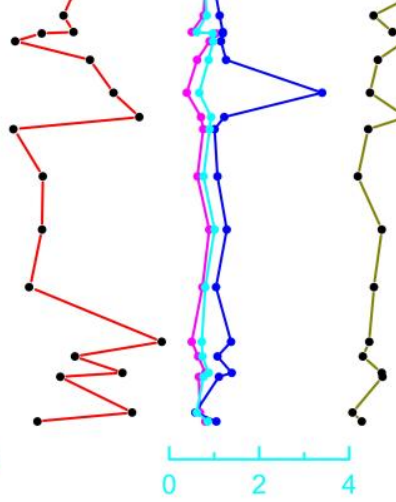

CPI

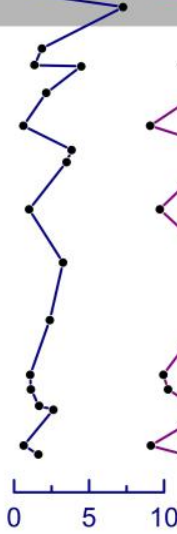

$\sum \mathrm{T} / \Sigma \mathrm{M}$

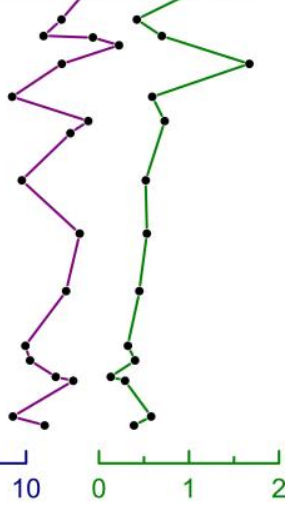

$\mathrm{Pr} / \mathrm{Ph}$

Fig. 2. Variations of iodine, $\mathrm{N}$-alkane and its diagnostic ratios in sediment samples.

The concentrations of iodine in sediment ranged from 0.03 to $2.54 \mu \mathrm{g} / \mathrm{g}$ with a median of $0.25 \mu \mathrm{g} / \mathrm{g}$. The highest concentration of iodine occurred in the the depth of $170-185 \mathrm{~m}$. The oceans presented the major reservoir in the global iodine cycle and microalgae were strong concentrators of iodine, as Manley [11] suggests that iodine accumulation by phytoplankton is considerably great. During the Quaternary, the events of marine transgression would carry marine organic matter such as microalgae and then the microbial degradation caused the releasing of iodine. Interestingly, the high iodine concentrations in sediments corresponded to the low values of TAR, $\sum \mathrm{T} / \sum \mathrm{M}$ and $\mathrm{ACL}$, and the consistent result also can be observed in Fig. 3b. This may reflect that marine source input is a predominant source of iodine. The overall low TOC content $(0.02-0.24 \%)$ in these sediments is typical of alluvial settings and alluvial sediments in general consist of degraded and reworked OM ${ }^{[13]}$, as demonstrated by UCMs and CPI. 


\subsection{The implications of iodine enrichment}
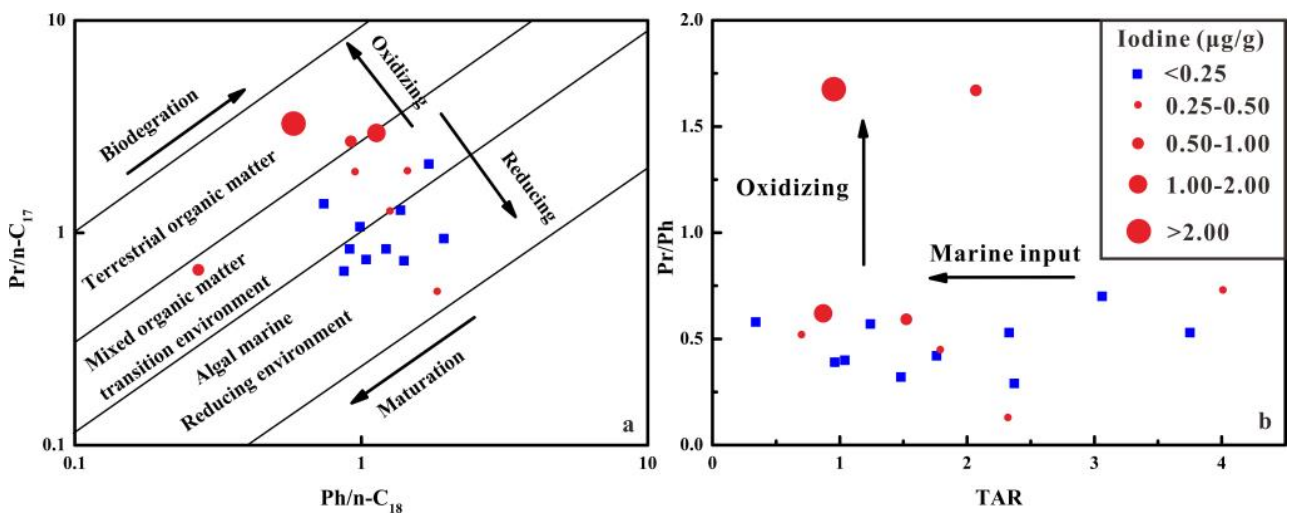

Fig. 3. Phytane to $n-C_{18}$ alkane $\left(\mathrm{Ph} / \mathrm{n}-\mathrm{C}_{18}\right)$ versus pristane to $\mathrm{n}-\mathrm{C}_{17}$ alkane $\left(\mathrm{Pr} / \mathrm{n}-\mathrm{C}_{17}\right)$ ratios (a) and the relationships between the Pristane/Phytane $(\mathrm{Pr} / \mathrm{Ph})$ and terrigenous/aquatic ratio (TAR).

The high iodine groundwater was distributed around the position of drill and the redox conditions could affect the migration of iodine ${ }^{[2,3]}$. The effect of redox condition on iodine enrichment during deposition is also provided by previous research conducted on recent marine sediment ${ }^{[14]}$, which suggests that high iodine concentration of oxidized sediment is mostly due to easier uptake of iodine relative to phytoplankton at the seafloor and iodine contained in planktonic matter originating in surface waters forms the bulk of iodine in reduced sediment. Besides, it is assessed iodine mobilization in the aerobic environment is less than in the anaerobic environment based on laboratory experiment of microalgae ${ }^{[15]}$. Different geochemical behavior of iodine is related closely to its species, which is also controlled by the redox condition ${ }^{[1,2]}$. In comparison with iodide, iodate, generally existing in oxic environment, is considered to have greater adsorption ability onto the OM or metal oxides/hydroxides ${ }^{[16]}$. In other words, iodate can be adsorbed significantly on to sediment under oxic environments. Therefore, it can be inferred that sediment can enrich iodine relative to marine organism under the relatively oxic condition and accumulate marine organism rather than enrich iodine directly under reductive condition. As shown in Fig. 2 and $3 \mathrm{a}$, the sediment iodine preferred abundance in oxidizing depositional environment $(\mathrm{Pr} / \mathrm{Ph}>1)$ to deficiency in reducing depositional environment $(\mathrm{Pr} / \mathrm{Ph}<1)$. It can be inferred that oxidizing condition support iodine retention onto sediment and reducing condition favors iodine migration. It is likely that the degradation of marine-source OM occurs under reducing depositional environment, resulting in migration of iodine from sediment to groundwater. Therefore, more detailed work is need to better understand the dominant factors controlling the iodine migration in aquifer systems.

\section{Conclusion}

The concentration of iodine in sediment have a high value at the depth of 170-185 m, which is affected by marine transgressive. Marine source input is the predominant factor controlling the concentration of iodine in sediment. In oxidized condition, iodine is more preferably enriched in sediment, and in reducing conditions, iodine is more easily migrated from sediment to groundwater.

The research was financially supported by National Natural Science Foundation of China (No. 41521001, 41502230 and 41772255) and the 111 Program (The State Administration of Foreign Experts Affairs \& the Ministry of Education of China Grant No. B18049). 


\section{References}

1. R. Fuge, C.C. Johnson, Appl. Geochem., 63, 282-302 (2015)

2. J. Li, H. Zhou, K. Qian, X. Xie, X. Xue, Y. Yang., Y. Wang, Sci. Total Environ., 598, 239-248 (2017)

3. X. Xue, J. Li, K. Qian, X. Xie, Earth Sci., 43(3), 910-921 (2018)

4. E. Zhang, Y. Wang, Y. Qian, T. Ma, D. Zhang, H. Zhan, Z. Zhang, Y. Fei, S. Wang, Journal of Geochem. Explor., 135, 40-53 (2013)

5. L. Bing, X. Ma, L. Han, H. Yang, Geostand. Geoanal. Res., 28 (2), 317-323 (2004)

6. S. Xu, Z. Xie, W. Liu, H. Yang, B. Li, Chin. J. Anal. Chem., 38 (2), 219-224 (2010)

7. G. J. Dević,; Z. V. Popović, Int. J. Coal Geol., 105, 48-59 (2013)

8. T. Wang, X. Fang, T. Zhang, Y. Li, Y. Wu , D. He, Y. Wang, Appl. Geochem., 25, 1478-1486 (2010)

9. H. D. Jr., W. G. Meinschein, D.E., Hattin, Geochim. Cosmochim. Acta., 40, 203-208 (1976)

10. B. R. T. Simoneit, Environ. Sci. \& Poll. Res,. 6, 159-169 (1999)

11. S.L. Manley, J. Phycol., 20, 192-201 (1984)

12. J. Lin, L. Dai, J. Palaeogeo., 1(2):105-125. 2012.

13. H. Rowland, D. Polya, J. Lloyd, R. Pancost, Org.Geochem., 37, 1101-1114 (2006)

14. N. Price, S. Calvert, Geochimica et Cosmochimica Acta., 37, 2149-2158 (1973)

15. W. Han, W. Clarke, S. Pratt, Bioresour. Technol. 193, 219-226 (2015)

16. J. Dai, M. Zhang, Q. Hu, Y. Huang, R. Wang, Y. Zhu, Geoderma, 153 (1-2), 130-135 (2009) 